\title{
Efficacy of holmium laser enucleation of the prostate in patients with detrusor underactivity: systematic review and meta-analysis
}

Ihsan Azka Adriansyah' ${ }^{1}$ Andika Afriansyah², Moammar Andar Roemare Siregar ${ }^{2}$, Nugroho Purnomo², Hendy Mirza ${ }^{2}$ and Doddy Hami Seno ${ }^{2^{*}}$

\begin{abstract}
Background: Benign prostatic hyperplasia (BPH) is commonly found in the aging male. Treatment of BPH can be in form of conservative or surgical intervention. Transurethral resection of the prostate (TURP) is the gold-standard treatment for BPH according to the guideline. However, there is no evidence that there is a benefit for TURP in patients with detrusor underactivity (DUA). Holmium laser enucleation (HoLEP) is theorized to have a better outcome due to its property of complete prostate enucleation. Therefore, this meta-analysis aims to determine the benefit of HoLEP for BPH patients with DUA.

Main body: We performed systematic literature searching from five databases including PubMed, Scopus, Embase, Science Direct, and Web of Science for articles up to 31 December 2020 for relevant studies. A total of five articles are eligible for this meta-analysis. A total of 2.180 subjects participated in all of the studies included. Two studies comparing patients with and without DUA that was treated with HoLEP, two studies comparing HoLEP with other surgical approaches for $\mathrm{BPH}$, and one study comparing both parameters. IPSS score reduction is significantly higher in the patients with DUA (Mean Difference $=3.28,95 \% \mathrm{Cl} 1.91$ to 4.64, $p<0.01$ ). $Q_{\max }$ and PVR are not significantly different between both groups. HoLEP also showed better improvement in IPSS and $Q_{\max }$ compared to TURP (IPSS: Mean Difference $=-4.80,95 \% \mathrm{Cl}-7.83$ to $-1.77, p=0.002 ; Q_{\max }$ : Mean Difference $=4.20,95 \% \mathrm{Cl} 0.58$ to $\left.7.82, p=0.02\right)$ and PVP (IPSS: Mean Difference $=-2.47,95 \% \mathrm{Cl}-4.47$ to $-0.47, p=0.02 ; Q_{\max }$ : Mean Difference $=2.31,95 \% \mathrm{Cl} 0.34$ to 4.28 , $p=0.02$ ).
\end{abstract}

Conclusion: HoLEP showed better improvement in IPSS scores in patients with DUA. HoLEP can be considered to be performed in the BPH patients with DUA for better outcomes for the patients.

Keywords: Benign prostatic hyperplasia, Detrusor underactivity, HoLEP, Surgical outcome, Laser enucleation

*Correspondence: doddy.uro@gmail.com

${ }^{2}$ Division of Urology, Department of Surgery, Persahabatan Hospital, Jl. Persahabatan Raya No. 1, Pulo Gadung, Jakarta Timur, DKI Jakarta 13230 Jakarta, Indonesia

Full list of author information is available at the end of the article

\section{Background}

Benign prostatic hyperplasia (BPH) is commonly found in the aging male, beginning at 40-45 years old and becoming $60 \%$ at 60 and $80 \%$ at 80 years old. A longitudinal study suggesting a prostate growth rate of $2.0 \%-2.5 \%$ per year in older men $[1,2]$. Treatments of choice for BPH are non-surgical and surgical intervention. Alpha-blocker and $5 \alpha$-Reductase inhibitors are the 
most common combination pharmacological therapy of options. In the past decades, there was a shift in managing BPH patients from surgical treatment to medical treatment. Prolonging the surgical, as a definitive treatment, makes patients have a risk for developing bladder de-compensation. Also, the urologist might face larger glands to operate. Approximately $25-30 \%$ of patients with BPH have detrusor underactivity (DUA). It makes surgical failure, such as minor improvement of International Prostate Symptoms Score (IPSS) and imperfect improvement of flow rate in the BPH with DUA patients [3]. Transurethral resection of the prostate (TURP) is become the gold-standard treatment of $\mathrm{BPH}$ and also as a reference to measure the efficacy, effectiveness, and safety of any other surgical treatments. A retrospective study that analyzed patients with DUA that underwent TURP showed no symptomatic or urodynamic benefit of the DUA patients who underwent TURP compared to no-treatment [4]. A dilemma could be faced as urologists, whether surgical therapy should proceed in this group of patients because of the conflicting results of the evidence.

Recently, there is an increase in using the laser to treat the $\mathrm{BPH}$. Holmium laser enucleation (HoLEP) is a surgical procedure that allows complete anatomical enucleations of the prostatic adenoma using a holmium laser [5]. A systematic review and meta-analysis of randomized clinical trials showed that HoLEP had a slightly better outcome in terms of IPSS score, flow rate, and residual urine volume compared to TURP in 12-months of followup [6]. HoLEP does have a potential therapeutic effect in BPH patients with DUA due to the ability of HoLEP to achieve near-complete de-obstructions. Patients might be voiding using low detrusor muscle contractility after alleviating the obstructions. However, the previous studies that examined the outcomes of HoLEP in men with detrusor underactivity have conflicting conclusions [7, 8]. Thus, we performed a systematic review and metaanalysis to evaluate the overall efficacy of HoLEP in BPH patients with detrusor underactivity.

\section{Main text}

\subsection{Methods}

\subsubsection{Selection and eligibility criteria}

The meta-analysis is written based on the Preferred Reporting Item for Systematic Reviews and Meta-Analyses (PRISMA) guidelines [9]. PICO (population, intervention, comparison, outcome) approach was used for identifying the studies included (Table 1).

Retrospective or prospective cohort and randomized or non-randomized trials are eligible for this study. There was no restriction on the year of publication and language included in this study. All non-English publication was translated before data extraction. The exclusion
Table 1 PICO approach

\begin{tabular}{ll}
\hline Population & BPH patients with detrusor underactivity \\
\hline Intervention & HoLEP \\
Comparison & Non-enucleation operations \\
Outcome & Postoperative IPSS, post void residual (PVR) \\
& volume, maximum flow rate $\left(Q_{\max }\right)$ \\
\hline
\end{tabular}

criteria were publication without full-text and data without comparison between HoLEP and the non- enucleation group. Authors of the abstracts from proceeding were contacted directly if the full text of the studies is ineligible.

\subsubsection{Search strategy}

Literature searching was conducted from five databases (PubMed, Scopus, Embase, Science Direct, and Web of Science). The search terms used were ("HoLEP OR Laser Enucleation") AND ("Benign Prostatic Hyperplasia OR BPH") AND ("Detrusor Underactivity OR DUA"). Two reviewers (I.A.A. and A.A.) performed independent screening in selecting the article. If there are differences from the screening, the reviewers conducted the discussion. An inconclusive debate was resolved by another author (D.H.S.). EndNote Reference Manager version X9 was used to identify and eliminate duplicate records from different databases.

\subsubsection{Data extraction and validity assessment}

Information needed from the articles was retrieved (population, intervention, comparison, outcome, results of each study) and summarized in Table 1 . Each study was assessed using the Newcastle-Ottawa Scale to evaluate the risk of bias [10]. Three factors were assessed for the risk of bias based on the Newcastle-Ottawa scale: (1) selection, (2) comparability, and (3) outcome of the study. Studies with a score of 7 or higher are categorized as good studies with a low risk of bias.

\subsubsection{Statistical analysis}

For the studies that provide relevant outcome data, the meta-analysis was conducted using the Cochrane Collaboration Review Manager (Rev-Man version 5.2) [11]. Data were differentiated into two analyses, firstly comparing subjects with detrusor underactivity and without detrusor underactivity and secondly comparing laser enucleation and non-enucleation operations. IPSS score, postvoid residual urine (PVR), and $\mathrm{Q}_{\max }$ score were analyzed using pooled mean difference with a confidence interval (CI) of $95 \%$. To identify the heterogeneity between studies, $\mathrm{C}^{2}$ and $\mathrm{I}^{2}$ were used. The study considers 
being heterogenous if the $\mathrm{I}^{2}>50 \%$ or of $\mathrm{C}^{2}<0.1$. Analysis with a $p$ value $<0.05$ was categorized as significant.

\subsection{Results}

Summarization of the article selection is described in Fig. 1. PRISMA diagram of the meta-analysis. Initial databases searching results in 247 studies, and all were imported into the Endnote application to remove duplicate records. The remaining 170 articles were assessed and selected based on the inclusion criteria through abstract and title screening. Eleven articles were further analyzed for eligibility and result in five articles from which the data were extracted for meta-analysis.

\subsubsection{Study characteristics}

From five studies that were analyzed [12-16], four were conducted in South Korea [12-15], and one study in the USA [16] (Table 2). All of the studies have minimal follow-up six months after the operation. Comparison of $\mathrm{BPH}$ patients with and without DUA are analyzed in two studies $[12,13]$. One study was comparing the usage of HoLEP and photoselective vaporization of the prostate (PVP) [16], and one study was comparing HoLEP and TURP [15]. One study by Cho et al. [14] comparing both
$\mathrm{BPH}$ patients with and without DUA and also comparing HoLEP and PVP in the same study. A total of 2.180 subjects participated in all of the studies included.

\subsubsection{Summary of study finding}

The summary of studies results is detailed in Table 2. A study comparing patients with and without detrusor underactivity result in better postoperative outcomes for patients without detrusor underactivity [12]. One study comparing HoLEP with PVP [16] and one study comparing HoLEP with TURP [15], found that patients with HoLEP surgery had better outcomes in the follow-up in the form of IPSS, $Q_{\max }$, PVR, and catheter-free rate. Table 3 showed the result of the quality assessment in assessing the risk of bias. All of the studies included have good quality based on the Newcastle-Ottawa scoring.

\subsubsection{Meta-analysis}

All of the studies were reported using estimated mean differences. Figure 2. is about forest plot of comparison between patients with and without detrusor underactivity in patients who underwent HoLEP, showed the patient's result with and without detrusor underactivity, while Fig. 3 presents a forest plot for the HoLEP and

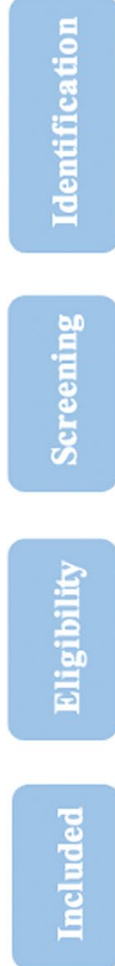

Records identifies through databases searching $(n=247)$

- PubMed $(n=39)$

- Scopus $(n=78)$

- Embase $(n=69)$

- Science Direct $(n=49)$

- Web of Science $(n=12)$

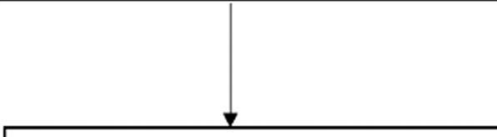

Records after removal of duplication studies $(n=170)$

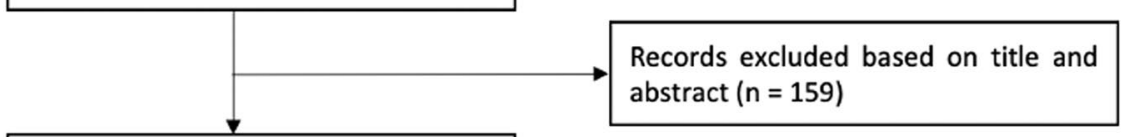

Full-text articles assessed for eligibility $(n=11)$ $(n=5)$ Full text excluded ( $n=6)$

- No comparison between HoLEP and other surgery methods $(n=2)$

- Not using HoleP as the exposure $(n=2)$

- Using the same patient's data $(n=2)$

Fig. 1 PRISMA diagram of the meta-analysis 


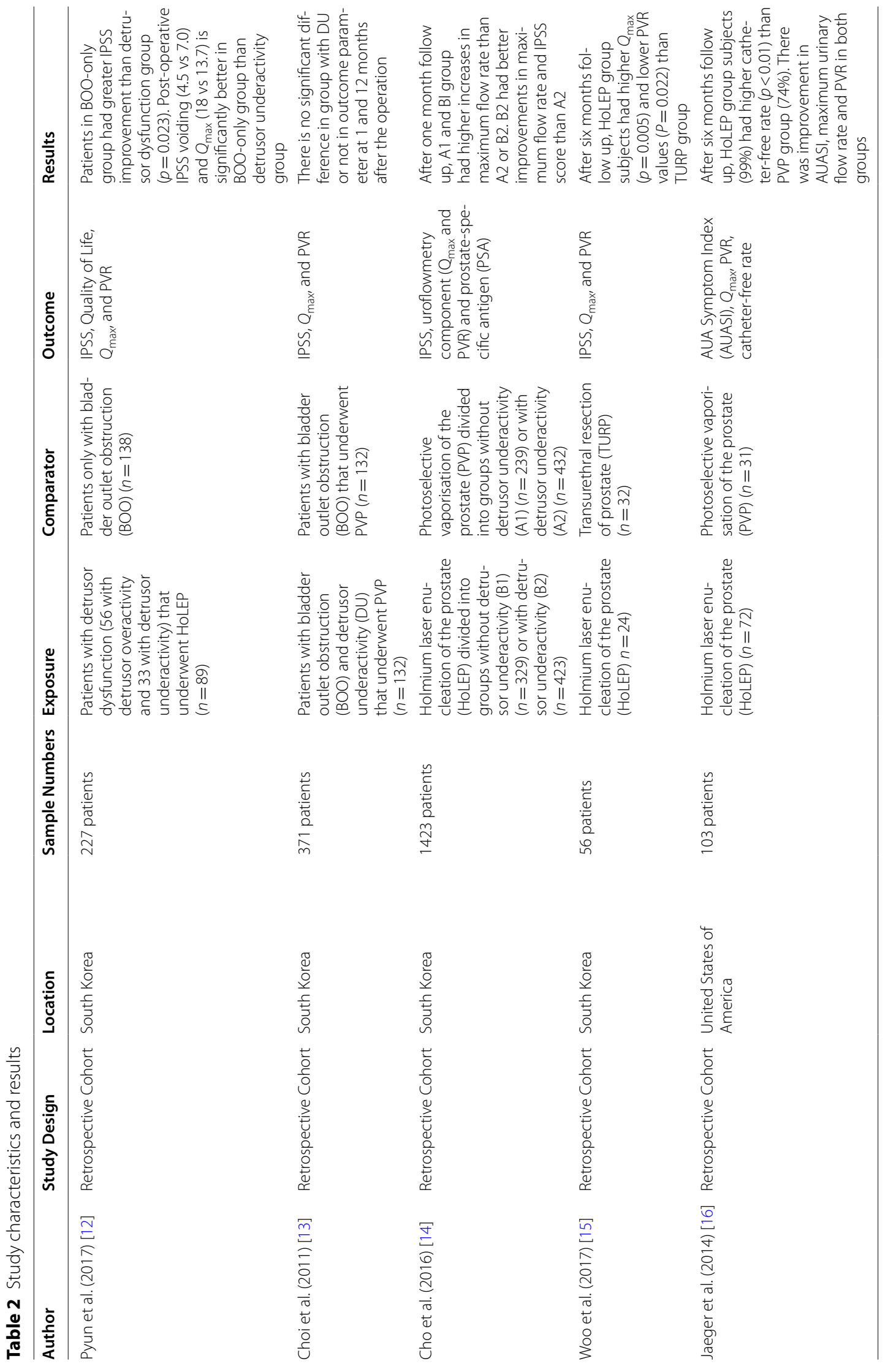


Table 3 Risk of assessment bias using Newcastle-Ottawa Scale

\begin{tabular}{|c|c|c|c|c|c|c|c|c|c|}
\hline \multirow[t]{2}{*}{ Author } & \multicolumn{4}{|l|}{ Selection } & \multirow{2}{*}{$\begin{array}{l}\text { Comparability } \\
\text { Comparability } \\
\text { of Cohorts }\end{array}$} & \multicolumn{3}{|l|}{ Outcome } & \multirow[t]{2}{*}{ Score } \\
\hline & $\begin{array}{l}\text { Representativeness } \\
\text { of the Exposed } \\
\text { Cohort }\end{array}$ & $\begin{array}{l}\text { Selection } \\
\text { of the } \\
\text { Non- } \\
\text { exposed } \\
\text { Cohort }\end{array}$ & $\begin{array}{l}\text { Ascertainment } \\
\text { of Exposure }\end{array}$ & $\begin{array}{l}\text { Demonstration } \\
\text { that Outcome } \\
\text { of Interest Was } \\
\text { Not Present at } \\
\text { Start of Study }\end{array}$ & & $\begin{array}{l}\text { Assessment } \\
\text { of Outcome }\end{array}$ & $\begin{array}{l}\text { Follow-up } \\
\text { Long } \\
\text { Enough } \\
\text { for } \\
\text { Outcome } \\
\text { to Occur }\end{array}$ & $\begin{array}{l}\text { Adequacy } \\
\text { of } \\
\text { Follow-Up }\end{array}$ & \\
\hline $\begin{array}{l}\text { Pyun } \\
\text { et al. } \\
(2017) \\
{[12]}\end{array}$ & 1 & 1 & 1 & 1 & 1 & 1 & 1 & 1 & 8 \\
\hline $\begin{array}{l}\text { Choi } \\
\text { et al. } \\
(2011) \\
{[13]}\end{array}$ & 1 & 1 & 1 & 1 & 1 & 1 & 1 & 1 & 8 \\
\hline $\begin{array}{l}\text { Cho } \\
\text { et al. } \\
(2016) \\
{[14]}\end{array}$ & 1 & 1 & 1 & 1 & 2 & 1 & 1 & 1 & 9 \\
\hline $\begin{array}{l}\text { Woo } \\
\text { et al. } \\
(2017) \\
{[12]}\end{array}$ & 1 & 1 & 1 & 1 & 1 & 1 & 1 & 1 & 8 \\
\hline $\begin{array}{l}\text { Jaeger } \\
\text { et al. } \\
(2014) \\
{[13]}\end{array}$ & 1 & 1 & 1 & 1 & 1 & 1 & 1 & 1 & 8 \\
\hline
\end{tabular}

non-HoLEP comparison. All of the forest plots had 95\% CIs and were presented in the mean difference.

\subsubsection{Detrusor underactivity vs non-detrusor underactivity}

Three studies comparing patients with DUA and nonDUA with the same postoperative outcome are analyzed [12-14] (Fig. 3. Forest plot of comparison between HoLEP and non-enucleation operations). IPSS analysis found that the patients without detrusor underactivity had a significantly lower IPSS score (Mean Difference $=3.28,95 \%$ CI 1.91 to $4.64, p<0.01) . Q_{\max }$ is also higher in patients without DUA, albeit it is not significant (Mean Difference $=-1.99,95 \% \mathrm{CI}-4.36$ to $0.38, p=0.10$ ). On the other hand, PVR (Mean Difference $=-1.61,95 \% \mathrm{CI}-0.15 .83$ to $12.60, p=0.82$ ), and favor the patients with detrusor underactivity the difference is not significant.

\subsubsection{HoLEP vs non-enucleation operations}

Three studies analyzed include IPSS, PVR, and $\mathrm{Q}_{\max }$ as the outcome of the study [14-16] (Fig. 2). From the IPSS measurement, it was found that the patients treated with HoLEP had significantly higher reduction in both comparison with PVP (Mean Difference $=-2.47$, 95\% CI -4.47 to $-0.47, p=0.02$ ) and TURP (Mean Difference $=-4.80,95 \% \mathrm{CI}-7.83$ to $-1.77, p=0.002)$. From the subgroup analysis, there is no difference between different operation methods (Mean Difference $=-3.18$, $95 \%$ CI -4.85 to $-1.51, p=0.21$ ) which indicates that there is no difference between TURP and PVP. Similar finding is also found in $Q_{\max }$, which HoLEP had higher $Q_{\max }$ compared to PVP (Mean Difference $=2.31$, 95\% CI 0.34 to $4.28, p=0.02$ ) and TURP (Mean Difference $=4.20$, 95\% CI 0.58 to $7.82, p=0.02$ ) with no significant result in subgroup analysis (Mean Difference $=2.74$, 95\% CI 1.01 to $4.47, p=0.37$ ). There are no differences in PVR in between laser and non-enucleation operations.

\subsection{Discussion}

$\mathrm{BPH}$ is a condition that can be treated conservatively or through a surgical approach. According to the European Association of Urology (EAU) guideline, TURP is still the golden standard in $\mathrm{BPH}$ management [17]. However, currently, there is no clear statement from the guideline regarding surgical management for $\mathrm{BPH}$ patients with DUA. Masumori et al. studied the effect of bladder outlet obstruction (BOO), DUA, and detrusor overactivity for the outcome of TURP and resulted in no influence of DUA in the change of IPSS and QOL. [18].

Prolong obstruction due to prostate enlargement is contributed to the occurrence of the DUA. In the animal model study that induced bladder outlet obstruction (BOO), the bladder was distended due to the rise in intravesical pressure. The detrusor muscle will become 


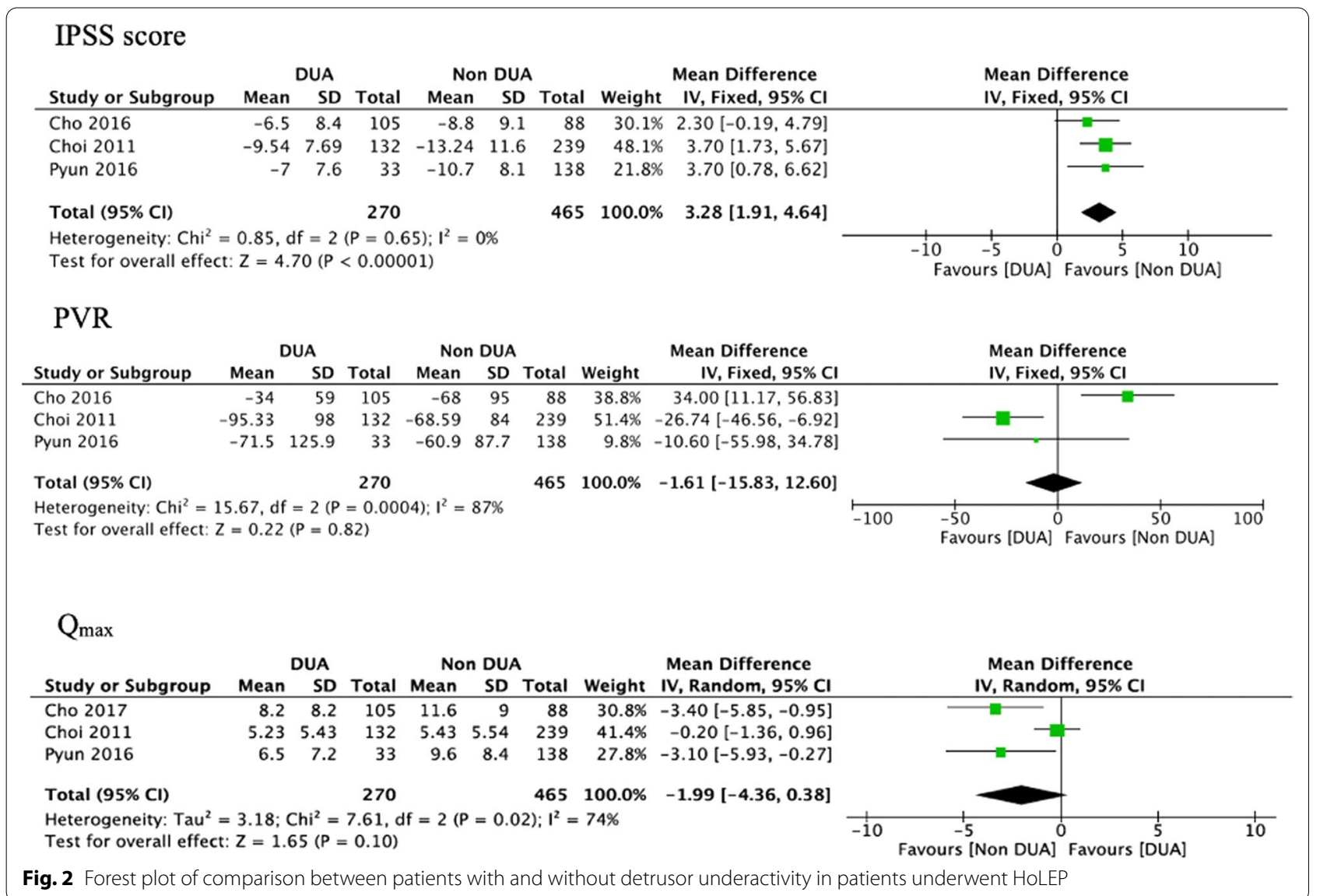

hypertrophy and increase vascularization as a compensation mechanism. However, if the obstruction is not relieved for some time, the bladder cannot compensate anymore and result in DUA due to impaired contractility. The mechanism underneath it is caused by cyclic ischemic and reperfusion injury resulting in the formation of reactive oxygen species (ROS) that impair cellular contractile function. Collado et al. also found that bladder obstruction caused detrusor remodeling that characterized by the deposition of collagen and elastic fibers in interfasciular and intrafasciular $[19,20]$.

Laser enucleation is hypothesized to have a better outcome in those patients. A study found that photoselective vaporization of the prostate and simultaneous suprapubic cystostomy can be options for $\mathrm{BPH}$ patients with DUA [6]. HoLEP is one of a type of laser enucleation and a newer alternative for BPH surgical treatment with better perioperative results such as lower blood loss and shorter length of stay. A previous study was conducted in determining the effect of HoLEP in patients with nonneurogenic impaired bladder contractility, and the results recommend HoLEP to be performed in those patients [8, 21].
Our meta-analysis compared two different surgical approaches and two different kinds of patients in understanding the effect of HoLEP in $\mathrm{BPH}$ patients with DUA. From the analysis in two other groups of patients, IPSS score reduction is also better in patients without DUA, with the average decline is around 3 points. We found contradictory findings in the PVR $(p=0.82)$ and $Q_{\max }(p=0.10)$, which tend to be better in the patients without DUA, even though the result is not significant. This finding has a similar result with a previous meta-analysis by Kim et al. that concludes that the absence of DUA is predictive for postoperative outcomes in $\mathrm{BPH}$ patients who underwent TURP [22]. In comparing HoLEP with PVP and TURP, IPSS score reduction and $Q_{\max }$ improvement are better in the patients who underwent HoLEP than the other two approaches. The subgroup analysis result confirms that the difference between PVP and TURP does not affect the result. A meta-analysis by Kim et al. showed a similar benefit of HoLEP compared to TURP in the result of better $Q_{\max }$ and IPSS score reduction for BPH patients with DUA and recommended HoLEP as the alternative to TURP [6]. 


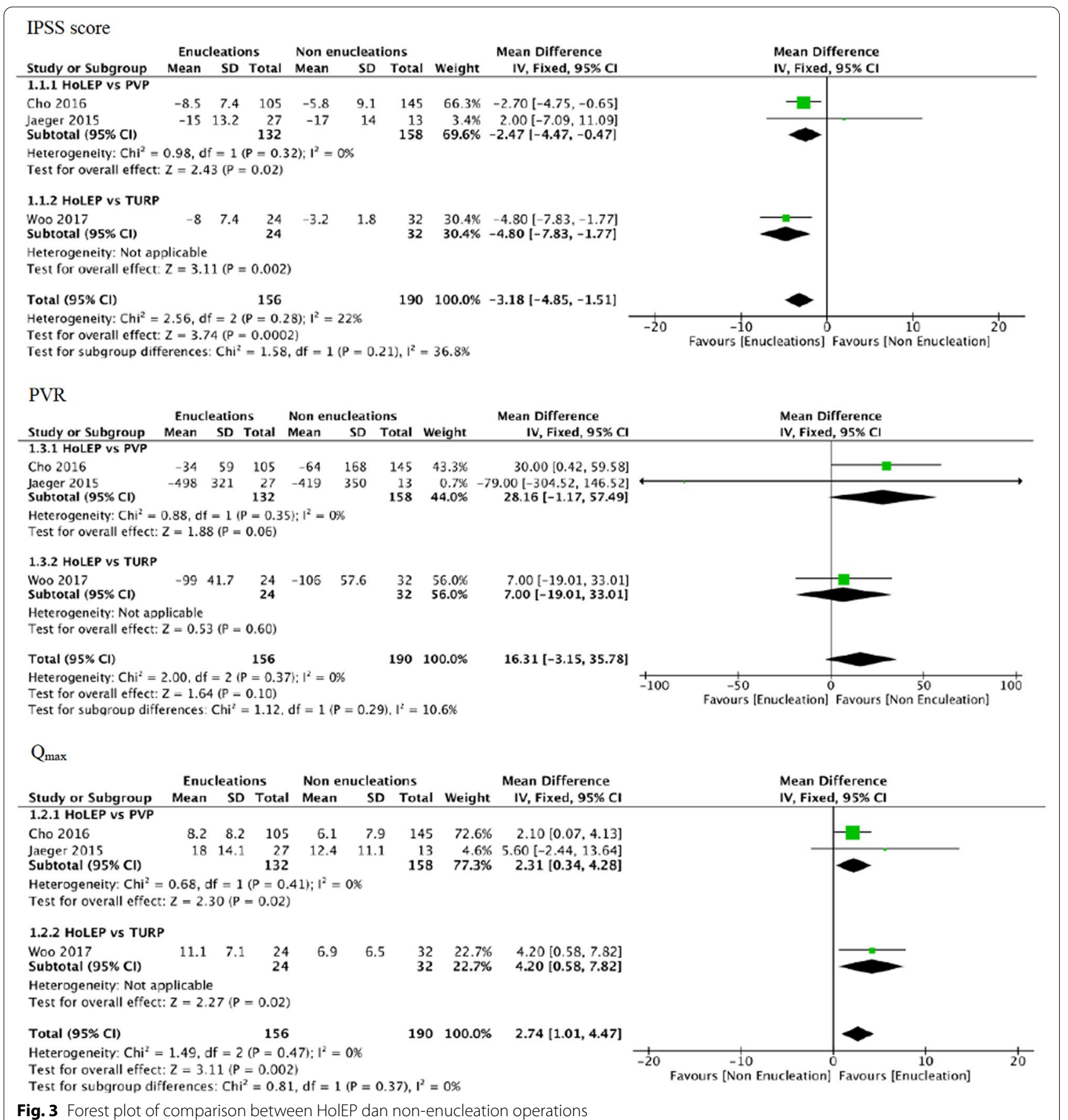

The strength of the articles that were analyzed is that the parameter that was used to determine the study result is measured properly with the proper method (IPSS questionnaire, uroflowmetry, or PSA) in determining the $\mathrm{BPH}$. The weakness of the articles that were analyzed is that most of the studies had short follow-up after the operation. Some of the articles are also retrospective studies, therefore the patients' baseline may be different in each group.
The strengths of the review are that, to our knowledge, this is one of the few meta-analyses comparing the surgical approaches in BPH patients with DUA. The review itself has also included a comprehensive search strategy with two independent reviewers for the article collections. All of the studies were a retrospective cohort and had the risk of loss to follow-up. Fortunately, all of the reviews complete the patients' follow-up until the designated time. All studies 
also had a low risk of bias based on the Newcastle-Ottawa Scale. The study has several limitations, such as the number of studies is still relatively low based on the database searching. There are several other studies aside that are used in this meta-analysis, but the focus of the research or the outcome measure does not suitable for this review criteria. The studies are also not randomized due to their study feasibility and ethical issues.

\section{Conclusion}

In conclusion, both the surgical modality and absence of detrusor dysfunction can be used as the prognosis factor in the postoperative outcome of BPH surgery. HoLEP is a better procedure in the $\mathrm{BPH}$ patients with DUA for better outcomes for the patients.

\section{Abbreviations}

$\mathrm{BPH}$ : Benign prostatic hyperplasia; TURP: Transurethral resection of prostate; DUA: Detrusor underactivity; HoLEP: Holmium laser enucleation; IPSS: International Prostate Symptoms Score; PVR: Postvoid residual urine; PVP: Photoselective vaporization of the prostate.

\section{Acknowledgements}

Not applicable

\section{Authors' contributions}

Study concept and design: I.A.A., A.A., and D.H.S. Acquisition of data: I.A.A., A.A., M.A.R.S., and N.P. Analysis and interpretation of data: I.A.A., A.A., H.M., and D.H.S. Drafting of the manuscript: I.A.A., A.A., and M.A.R.S. Critical revision of the manuscript: N.P., H.M., D.H.S. Study supervision: H.M., D.H.S. All authors read and approved the final manuscript.

\section{Funding}

No funding was obtained for this study.

\section{Availability of data and materials}

The data and materials can be obtained by contacting the corresponding author.

\section{Declarations}

Ethics approval and consent to participate Not applicable.

\section{Consent for publication}

Not applicable.

\section{Competing interests}

The authors declare that they have no competing interests.

\author{
Author details \\ 'Department of Urology, Faculty of Medicine, Universitas Indonesia, J. Dipo- \\ negoro No. 71, Salemba, Jakarta Pusat, DKI Jakarta 10430 Jakarta, Indonesia. \\ ${ }^{2}$ Division of Urology, Department of Surgery, Persahabatan Hospital, J. Per- \\ sahabatan Raya No. 1, Pulo Gadung, Jakarta Timur, DKI Jakarta 13230 Jakarta, \\ Indonesia.
}

Received: 16 May 2021 Accepted: 2 September 2021

Published online: 10 September 2021

\section{References}

1. Loeb S, Kettermann A, Carter HB, Ferrucci L, Metter EJ, Walsh PC (2009) Prostate volume changes over time: results from the Baltimore Longitudinal Study of Aging. J Urol 182(4):1458-1462

2. Bosch JL, Tilling K, Bohnen AM, Bangma CH, Donovan JL (2007) Establishing normal reference ranges for prostate volume change with age in the population-based Krimpen-study: prediction of future prostate volume in individual men. Prostate 67:1816-1824

3. Tanaka Y, Masumori N, Itoh N, Furuya S, Ogura H, Tsukamoto T (2006) Is the short-term outcome of transurethral resection of the prostate affected by preoperative degree of bladder outlet obstruction, status of detrusor contractility or detrusor overactivity? Int J Urol 13(11):1398-1404

4. Thomas AW, Cannon A, Bartlett E, Ellis-Jones J, Abrams P (2004) The natural history of lower urinary tract dysfunction in men: the influence of detrusor underactivity on the outcome after transurethral resection of the prostate with a minimum 10-year urodynamic follow-up. BJU Int 93(6):745-750

5. Aho TF (2013) Holmium laser enucleation of the prostate: a paradigm shift in benign prostatic hyperplasia surgery. Ther Adv Urol 5(5):245-253

6. Yin L, Teng J, Huang CJ, Zhang X, Xu D (2013) Holmium laser enucleation of the prostate versus transurethral resection of the prostate: a systematic review and meta-analysis of randomized controlled trials. J Endourol 27(5):604-611

7. Cho MC, Park J, Kim JK, Cho SY, Jeong H, Oh SJ et al (2018) Can preoperative detrusor underactivity influence surgical outcomes of 120 W HPS vaporization of the prostate (PVP) or holmium laser enucleation of the prostate (HoLEP)? A serial 3-year follow-up study. Neurourol Urodyn 37(1):407-416

8. Mitchell CR, Mynderse LA, Lightner DJ, Husmann DA, Krambeck AE (2014) Efficacy of holmium laser enucleation of the prostate in patients with non-neurogenic impaired bladder contractility: results of a prospective trial. Urology 83(2):428-432

9. Liberati A, Altman DG, Tetzlaff J, Mulrow C, Gotzsche PC, loannidis JP et al (2009) The PRISMA statement for reporting systematic reviews and metaanalyses of studies that evaluate healthcare interventions: explanation and elaboration. BMJ 339:b2700

10. Luchini C, Stubbs B, Solmi M, Veronese N (2017) Assessing the quality of studies in meta-analyses: Advantages and limitations of the Newcastle Ottawa Scale. World J Meta-Anal 5:80-84

11. Wang J, Leeflang M (2019) Recommended software/packages for metaanalysis of diagnostic accuracy. J Lab Precis Med 4:22

12. Pyun JH, Kang SG, Kang SH, Cheon J, Kim JJ, Lee JG (2017) Efficacy of holmium laser enucleation of the prostate (HoLEP) in men with bladder outlet obstruction (BOO) and non-neurogenic bladder dysfunction. Kaohsiung J Med Sci 33(9):458-463

13. Choi SW, Choi YS, Bae WJ, Kim SJ, Cho HJ, Hong SH et al (2011) 120 W greenlight hps laser photoselective vaporization of the prostate for treatment of benign prostatic hyperplasia in men with detrusor underactivity. Korean J Urol 52(12):824-828

14. Cho MC, Ha SB, Park J, Son H, Oh SJ, Kim SW et al (2016) Impact of Detrusor underactivity on surgical outcomes of laser prostatectomy: comparison in serial 12-month follow-up outcomes between potassiumtitanyl-phosphate photoselective vaporization of the prostate (PVP) and holmium laser enucleation of the prostate (HoLEP). Urology 91:158-166

15. Woo MJ, Ha YS, Lee JN, Kim BS, Kim HT, Kim TH et al (2017) Comparison of surgical outcomes between holmium laser enucleation and transurethral resection of the prostate in patients with detrusor underactivity. Int Neurourol J 21(1):46-52

16. Jaeger CD, Mitchell CR, Mynderse LA, Krambeck AE (2015) Holmium laser enucleation (HoLEP) and photoselective vaporisation of the prostate (PVP) for patients with benign prostatic hyperplasia (BPH) and chronic urinary retention. BJU Int 115(2):295-299

17. Lokeshwar SD, Harper BT, Webb E, Jordan A, Dykes TA, Neal DE Jr et al (2019) Epidemiology and treatment modalities for the management of benign prostatic hyperplasia. Transl Androl Urol 8(5):529-539

18. Masumori N, Furuya R, Tanaka Y, Furuya S, Ogura H, Tsukamoto T (2010) The 12-year symptomatic outcome of transurethral resection of the 
prostate for patients with lower urinary tract symptoms suggestive of benign prostatic obstruction compared to the urodynamic findings before surgery. BJU Int 105(10):1429-1433

19. Aldamanhori R, Osman NI, Chapple CR (2018) Underactive bladder: pathophysiology and clinical significance. AJUR 5:17-21

20. Collado A, Batista E, Gelabert-Más A, Corominas JM, Aranó P, Villavicencio $H$ (2006) Detrusor quantitative morphometry in obstructed males and controls. J Urol 176(6 Pt 1):2722-2728

21. Yu Z, Li J, Li Z, Hou R (2015) Photoselective vaporization of the prostate and simultaneous suprapubic cystostomy for the treatment of benign prostatic hyperplasia in patients with mild to severe detrusor underactivity. Urol Int 95(3):269-275

22. Kim M, Jeong CW, Oh SJ (2018) Effect of preoperative urodynamic detrusor underactivity on transurethral surgery for benign prostatic hyperplasia: a systematic review and meta-analysis. J Urol 199(1):237-244

\section{Publisher's Note}

Springer Nature remains neutral with regard to jurisdictional claims in published maps and institutional affiliations.

\section{Submit your manuscript to a SpringerOpen ${ }^{\circ}$ journal and benefit from:}

- Convenient online submission

- Rigorous peer review

- Open access: articles freely available online

- High visibility within the field

- Retaining the copyright to your article

Submit your next manuscript at $\boldsymbol{\nabla}$ springeropen.com 